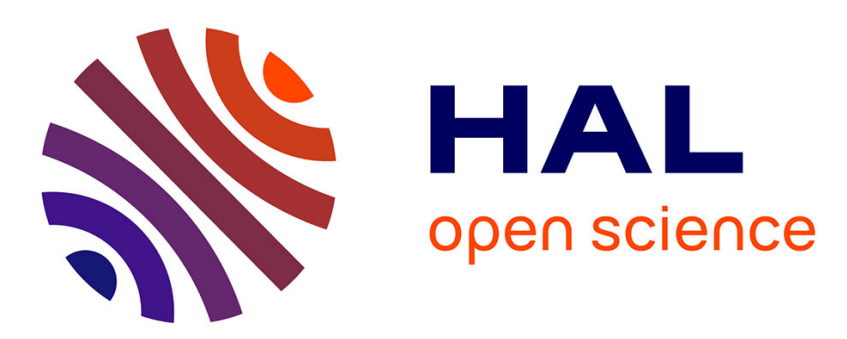

\title{
Assessing the Suitability of Supplier Consortia for Public Procurement Contracts
}

\author{
Andrew Crossley, Jane Lynch, Sue Hurrell, Rhian Edwards
}

\section{To cite this version:}

Andrew Crossley, Jane Lynch, Sue Hurrell, Rhian Edwards. Assessing the Suitability of Supplier Consortia for Public Procurement Contracts. 17th Working Conference on Virtual Enterprises (PROVE), Oct 2016, Porto, Portugal. pp.189-199, 10.1007/978-3-319-45390-3_17 . hal-01614593

\section{HAL Id: hal-01614593 \\ https://hal.inria.fr/hal-01614593}

Submitted on 11 Oct 2017

HAL is a multi-disciplinary open access archive for the deposit and dissemination of scientific research documents, whether they are published or not. The documents may come from teaching and research institutions in France or abroad, or from public or private research centers.
L'archive ouverte pluridisciplinaire HAL, est destinée au dépôt et à la diffusion de documents scientifiques de niveau recherche, publiés ou non, émanant des établissements d'enseignement et de recherche français ou étrangers, des laboratoires publics ou privés. 


\title{
Assessing the Suitability of Supplier Consortia for Public Procurement Contracts
}

\author{
Andrew Crossley ${ }^{1,2}$, Jane Lynch $^{3}$, Sue Hurrell ${ }^{4}$, Rhian Edwards ${ }^{5}$ \\ ${ }^{1}$ ServQ Alliance, Cardiff, Wales, UK \\ AndrewDCrossley@ServQ.com \\ ${ }^{2}$ University of Bristol, Bristol, UK \\ ${ }^{3}$ Cardiff Business School, Cardiff, Wales, UK \\ ${ }^{4}$ Values Wales, Welsh Government, Cardiff, Wales, UK \\ ${ }^{5}$ Wales Co-operative Centre, Caerphilly, Wales, UK
}

\begin{abstract}
This study offers a unique contribution to the existing research on collaborative working by exploring the buy side challenges facing public procurement teams when managing Collaborative Network Organizations (CNOs) termed 'supplier consortia' in this study. Two online management tools are proposed. A Procurement Assessment Model (PAM) guides buyers in assessing the suitability of public contracts for consortia bids. A Bid/No Bid model is offered to help suppliers align their $\mathrm{CNO}$ to the procurement and specification. This study is relevant for the public and private sectors but both tools proposed have been adopted by the Welsh Government (UK) and included as updates within the formal Joint Bidding Guide. The Joint Bidding Guide has been developed, published and tested by the Welsh Government since 2013.
\end{abstract}

Keywords: Supplier Selection; Joint Bidding; Consortia, Public Procurement; Tendering Process

\section{Introduction}

Significant technological advancements, such as the internet of things and Cyberphysical systems address the interconnection and collaboration among physical and virtual objects which expedites knowledge creation and growth opportunities for organizations [1]. The new competitive landscape [2] has enabled a significant rise in different forms of Collaborative Network Organizations (CNOs) operating through cloud computing, virtual communities, business ecosystems and other software [3].

Horizontal collaboration in the supply market, forming CNOS of supplier consortia leads to unprecedented organizational growth opportunities as commonly noted in logistics research [4] and e-commerce research [5]. Yet in the public procurement context there are many challenges and perceived barriers identified for Small and Medium Sized Enterprises (SMEs) when trying to compete against larger conglomerates for public contracts [6]. The purpose of forming networks or consortia is "to build a collaborative advantage in which multiple organizations together achieve something that individual organizations could not achieve alone” [3]. 
Using an abductive approach, and multiple methods which involve academics, public procurement practitioners and supplier case studies this paper explains the rationale and development behind the design and adoption of two powerful procurement tools. These relate to the suitability and selection of a supplier consortium and can be implemented during two critical stages of the public sector procurement process. During the first stage the client and procurement team assess whether bids from consortia are likely to be successful. During the second stage the tender opportunity is assessed as viable for delivery by consortium members working as a virtual network (VN) or using the lead model as a virtual enterprise (VE) [7].

The paper introduces the key influencing studies for horizontal collaboration, supplier selection, procurement assessment and related maturity models. Once the methodology has been explained, the findings are presented and the two models proposed as procurement tools form the main research contributions and conclusions.

\section{Literature Review}

\subsection{Supplier Consortium Development}

Aside from logistics research [4] and studies examining the e-commerce supply chain [5] much of the existing research on horizontal collaboration through consortia development has been applied to the buy side in procurement [7] [8] with limited research examining supplier consortia [8] [9]. Two key procurement studies were identified which highlighted the importance of selecting the appropriate organizational form for developing a consortium [8] [10]. Parallels were identified in the literature between recommendations for procurement and how these collaborative forms may apply to the supply market. Firstly, Bakkar et al. [8] established seven collaborative forms worthy of serious consideration: professional network; piggy backing; shared services; lead-buying; third party advisory; third party joint purchasing and third party outsourced. Piggy backing, third party advisory or the lead buying model can also be argued as the most suitable strategy designs for managing supplier consortia. Secondly, Cagnuzzo et al. [10] highlighted Industrial Clusters, Districts, Virtual Organizations (VOs), Virtual Enterprises (VEs), Virtual Breeding Environment (VBE) and Collaborative Networks (CNOs). Governance is also reviewed in Rabelo et al. [11].

The practice of suppliers bidding jointly is not new, sometimes termed in the private sector as bundling, clustering or co-option [6]. Team building, staff engagement and trust were identified as key determinants for effective supplier consortia [9]. However, collaborative relationships are complex to manage as consortium members may be challenged with conflicting organizational cultures and approaches to leadership [3]. Further problems are likely when managing mutual benefit arrangements and information asymmetry [7].

\subsection{Consortia and Economic Sustainability}

The initiation of a public tender requires that the Client's 'make or buy' decision has been made at the outset. One important decision is whether the tender is suited to SMEs because there are social and economic community benefits for public contracts to be 
awarded to and delivered by smaller, local suppliers [12]. As the UK public sector faces times of increasing austerity, forced restructuring and centralization of procurement has meant that contract values have increased. This makes it difficult for SMEs to compete against larger conglomerates [6] [9]. SMEs bidding individually can also potentially represent higher financial risk to public buyers [6] [13]. Therefore, one solution for the Client to accept consortia bids is adapting either the lead model or piggy backing methods managed as a virtual enterprise (VE) [8] [10].

\subsection{Procurement Assessment Models}

The first of the assessment tools designed in Wales, called the Procurement Assessment Model (PAM), was created in 2013 for procurement teams to support efficient evaluation of the most relevant 'buy side' and 'supply side' factors influencing the likely success of consortium delivery [14]. The first PAM was designed as a decision enhancing tool rather than a decision making tool. This approach responded to the gap for appropriate research and evidence on collaborative procurement methods developed from case studies, highlighted by Cagnazzo et al. in their literature review. In 2013 supply side collaboration and virtual networks had not been actively encouraged by many client and procurement officers in Wales' public sector [13]. Hence procurement teams were inexperienced in developing consistent and fair supplier selection criteria to compare a consortium bid with one from a single organization. The software industry's Capability Maturity Model Integration (CMMI) and the newer international standards on software maturity assessment [15] were considered too specific for the PAM's assessment criteria. Instead, the first British Standard for Collaborative Working [16] offered a standard relationship maturity matrix using a four-point qualitative measurement scale ranging from limited application to high level of maturity, and this was a useful basis for the development.

\subsection{Supplier Selection}

The research on supplier selection is extensive ${ }^{1}$. Recent methods for determining supplier selection criteria seem to be weighted towards stochastic, analytical hierarchy process (AHP) and fuzzy AHP [17] [18]. Yet, studies relevant for public procurement are few. This is surprising given that procurement teams are pressured into using scoring mechanisms to ensure fairness, transparency and consistency [17] [19]. Increasingly the traditional lowest cost or "Most Economically Advantageous Tender" (MEAT) [19] [20] approaches to selection are being supplemented by value-adding sustainability criteria, for example by including social, economic and environmental community benefits [12]. Potential supplier consortia self-selection is also vital within an efficient procurement system, and a Bid/No-Bid model was also developed to facilitate this. It assesses five key areas: market positioning; bidding resource and availability; delivery competence; commercial acceptability; and risk [14].

\footnotetext{
${ }^{1}$ Google Scholar identified 37,400 published studies using "supplier selection" as the search terms $[15 / 06 / 16]$
} 


\subsection{Review Summary}

Most of the existing studies examined for this review have focused more on different forms of collaboration in the procurement context. Yet, there are many lessons and transferrable concepts which can be explored for managing collaboration in the supply market. The review has emphasized that collaboration across SMEs improves performance through knowledge transfer and business growth opportunities [1] [6] [10]. Future research is invited exploring models for the private sector using hard, quantitative measurements rather than soft, qualitative measures [7] [19]. This provides the basis and rationale for the new PAM development.

In response to the economic tensions affecting public procurement in Wales and other parts of the UK, supplier consortia are being encouraged [9] [13] [14]. In 2012 the Welsh Government introduced a procurement policy statement which highlighted the importance of widening SMEs' access to public sector tenders. This led to the development of the Joint Bidding Guide (JBG) in 2013. The background to the Guide was published in 2015 [13], introducing the rationale for a successful series of Joint Bidding Demonstration Projects that ran between 2014 and 2015. Accepting important messages from the literature and research gaps as highlighted, this paper explores the key lessons learned from these Demonstration Projects, developing updated consortium models for procurement assessment and supplier bid selection.

\section{Method}

This study lends itself to an abductive research approach, established by Blaikie [21]. Abductive research is argued as offering a similar approach to inductive research or grounded theory as it relies primarily on existing prior knowledge and theory testing [21]. Theory, data collection and data analysis are managed simultaneously for developing new theory [22]. In total, six years of desk research $(2010-2016)$, modelling design, field trials, feedback, review and updates have taken place. The subsequent Lessons Learned Report (LLR) published by Welsh Government in 2015 highlighted key development areas from Demonstration Projects [23]. The important Lessons Learned were based on the outcomes and experiences of managing twelve Demonstration Projects and the findings summarized from a series of interviews with senior procurement managers, procurement teams, procurement policy advisors, suppliers and steering group members. After publication of the LLR the Joint Bidding Steering Group agreed that enhancements were needed to the Procurement Assessment Model (PAM) designed for the original Guide. The Lessons Learned from the Demonstration Projects were presented at Cardiff Business School in late 2015. The LLR and literature findings form the basis for the two new consortium models featured in this study.

\section{Model Development - Procurement Assessment Model (PAM)}

Prior to determining the new supplier selection criteria, four areas were considered from the LLR which highlights the suitability of a contract for consortium delivery: 
1) Enhance Decision Making - PAM should be used in the earliest stages of procurement planning; 2) Maturity Indices - The relationship management plan from BS 11000-1:2010 [16] was enhanced using the supporting guide for the British Standard (BS11000-2:2011) [24]; 3) Heat Map - highlighting Red/Amber/Green (RAG) configuration. This format was readily accepted by senior decision makers in their risk analysis and management work; and 4) High Level Characteristics of Suppliers - strategy and operations covering location, production (or service provision), inventory and transportation/distribution were to be accounted for.

The procurement experts and suppliers interviewed emphasized the importance of pre-market engagement with the supply market as key to the success of consortium development and receiving joint bids. Specific tenders were advertised as suitable for consortium delivery using the online national tender e-portal and database known as Sell2Wales [25] along with early engagement meetings for potential suppliers.

Following the demonstration projects, feedback received from the interviews and field trials established that the PAM approach was potentially very effective. However, on closer review the LLR recommended that more detail was required to optimize the model's effectiveness. Key areas needing improvement include: a) separation of the buy side and supply side factors; b) introduction of summary descriptions guiding the PAM users on where their project or service sat on the horizontal continua; c) expansion of the number of continua factors to twelve plus one additional option, and; d) more introductory and explanatory text.

Steering group members questioned whether some form of weighting to score the overall model with pass/fail criteria was appropriate. This expert user group preferred the model to be used as an indicator of suitability. In principle, where there are a significant number of red and/or amber assessment points emerging, the procurement team should firstly review whether practical tactics can be used to reduce the RAG 'heat' such as repackaging the delivery location or size of lots (continua points 3 and 7 for example, in the Buy Side Factors). When this is possible the opportunity is better prepared for potential consortia.

At the time of writing, the web engineers appointed by the Welsh Government to manage the tender e-portal Sell2Wales were designing the relevant 'tick box' for highlighting suitability for consortia bidding and delivery. Ticking the advertisement's box stating 'the procurers believe that this opportunity is suitable for delivery by consortia' gives a very strong indication to the market that the buy side is amenable to receiving joint bids. One of the most striking findings from discussions with successful consortium bidders on the Demonstration Projects was that this initial positive statement is one of the most important factors in encouraging bids from existing or newly-formed consortia. From the supply side's perspective, a positive endorsement on the Sell2Wales portal indicates that the PAM has been run and the opportunity is well suited to joint bidding. Conversely the buy side not ticking the box, to state the opportunity is suitable for joint bidding, could sensibly infer that the opportunity is considered as either marginal or not really suited for joint bidding.

For procurements subject to the UK Public Contracts Regulations 2015 [26], consortium bids must not be excluded, although consortia can be required to form a legal entity for contractual purpose. For procurements where the PAM shows red and amber indicators the procurement team may decide not to actively market the opportunity as consortium-friendly. 


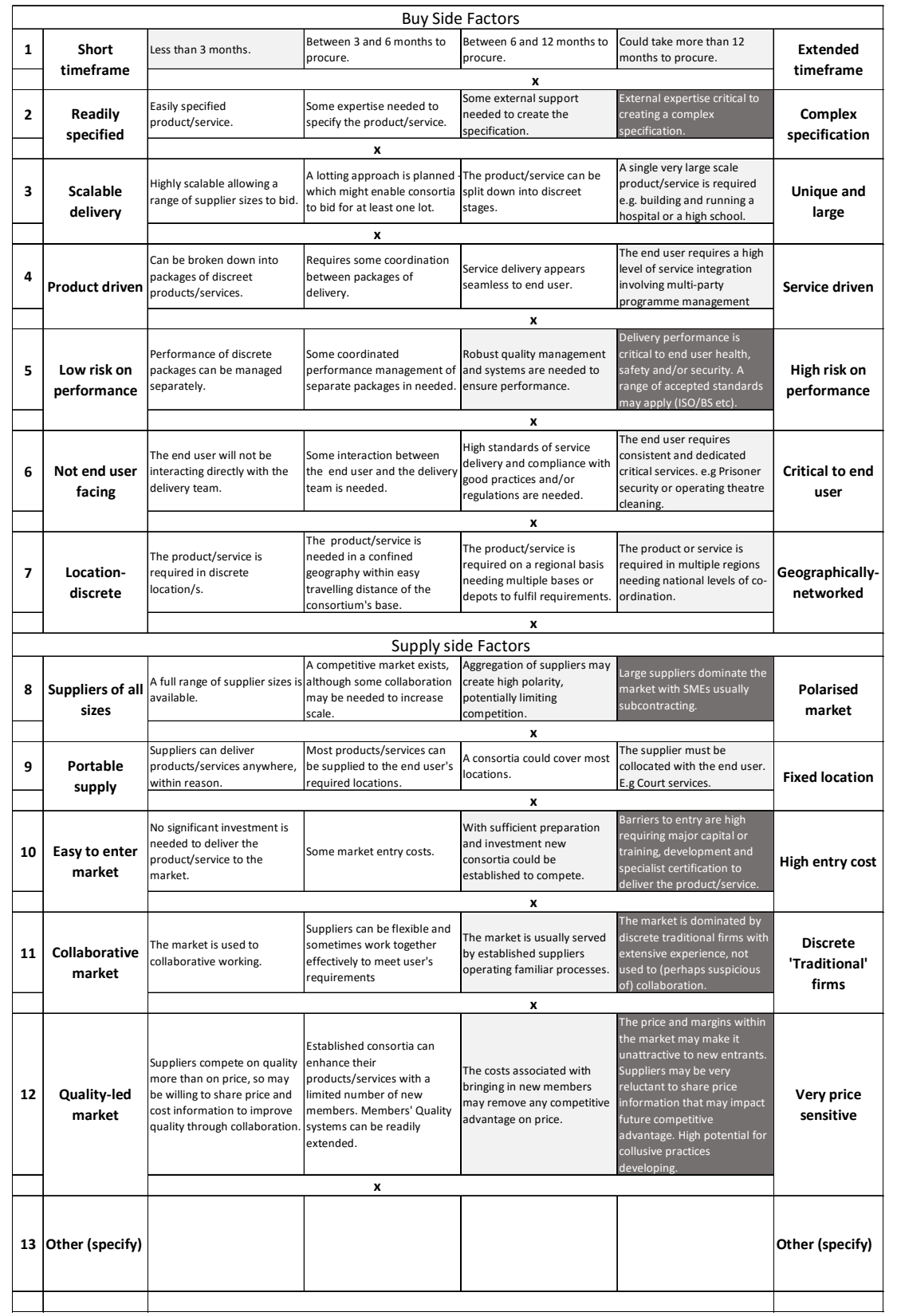

Fig. 1 Procurement Assessment Model (PAM) used for a Supply Teachers' tender 
Figure 1 contains the upgraded PAM in response to points a) separation of buy side and supply side factors and d) including more introductory and explanatory text.

The upgraded PAM builds on both the literature findings and the findings of the Demonstration Projects. Using a RAG 'traffic light' approach for the continua factors, red zones (dark grey) indicate potential areas or issues with the procurement that make it less amenable to joint bidding. Amber zones (light grey) suggest that consortium delivery may pose some challenges, whereas green zones (white) suggest that the procurement is most suitable for consortium delivery. In this worked example the crosses $(\mathrm{X})$ reflect the following assessment by the procurement team:

Buy side factors - There is time to prepare a framework tender; it is clearly specified; it is scalable; it is mainly service driven (time and location); it is a reasonable risk on performance (staff experience); it directly interfaces with end users (with access restrictions) and it is needed at many schools for a council.

Supply Side factors - There are incumbent providers who try and control the market via sub-contracting; a consortium can cover most locations within the council area; qualified teachers can create consortia (with access restrictions); with sufficient planning and infrastructure new consortia can compete effectively; the market is currently served by established suppliers; new members can add appropriate volume.

The conclusion from this PAM analysis is that the Supply Teachers contract, could be delivered by a consortium but there are some potential risks to be considered prior to contract advertisement. The PAM may also help buyers to consider re-packaging the demand to make it more attractive to consortia and/or smaller businesses. It is a useful model for identifying risk where red and amber indicators indicate that tender questions should ensure that supplier consortia have Relationship Management Plans [23] [24] and written agreements in place where necessary to manage risk of failure.

\section{Model Development - The Bid/No-Bid Model}

Chapter 9 of the JBG contains advice on how a potential consortium should review the opportunity: "As the initiating member of a consortium you will need good quality tools and a basic opportunity assessment process to work out how to proceed. If you already have a consortium you should agree which of your members have the best tools for this stage." The Bid/No-Bid model uses 44 points of assessment in these 5 key areas: 1) Consortium's market positioning; 2) Bidding resource and availability; 3) Consortium's delivery competence; 4) Commercial issues; and, 5) Risk planning. ${ }^{2}$

Figure 2 is a worked example of two key areas from a consortium Bid/No-Bid model. The other three areas have a similar form of evaluation. There is an overall dashboard with the key area scores mapped against an upper and lower boundary. An example of this is given in Chapter 9 Annex A of the Joint Bidding Guide.

\footnotetext{
2 The maximum score for each assessment point is 5 . The model uses a semi-logarithmic approach to scoring (Unknown, $0,1,3,5$ ) to avoid 'mid-point' scoring bias from linear scales. A maximum score of 5 for each assessment point would yield a theoretical maximum total of 220 for the 44 points of assessment. Each key area has its own score to highlight which areas merit special attention.
} 


\section{Assessment Templates}

Mark each question from 0 to 5 or as Unknown (Unk) if not currently known

5 Excellent position for proposed Consortiun

Good position for proposed Consortium

Basic position for proposed Consortium

Not curre

Consortium's Market Position

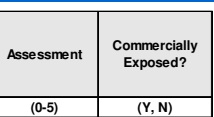

1 Is this opportunity a good fit with our Consortium's goals?

Will winning enhance our Consortium's reputation and market positioning?

Will winning open up new market opportunities for our Consortium?

Are any members of our Consortium known to the key decision makers?

Does any member of our Consortium understand the imperative need or problem drving this opportunity?

Do we know the opportunity's evaluation criteria and how they will be weighted?

Do we know the proposal time frame?

Do our Consortium's features and benefits give it a distinct competitive advantage?

Can we compete if price is a major factor in selecting the winning bid?

Do any of our members have successful track records with similar opportunities?

Does our Consortium have differentiators that improve its odds of winning this opportunity?

Does the Consortium know who the other competitive bidders are, if any?

Can we win against a good competitor if it is currently in post?

14 Will winning this opportunity give our Consortium future business advantage over its competitors?

1 Consortium's Market Position Score: (Maximum of 70 points)

Percentage score:

Total number of scores rated as 0 (Very weak position for Consortium):

Total number of scores rated as Unk (Unknown):

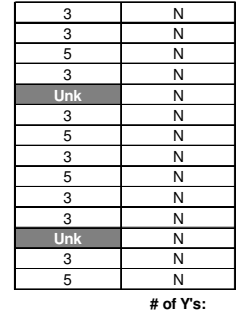

Action to Improve Scoring: Need to get a better understanding of the requirements and demands that have led to this tender (5). At the moment we do not know who the competitors are likely to be (12). There is a meet the buyer event planned so we can see who is there.

\section{Bidding Resource Availability}

15 Does the Consortium have a Bid Director qualified to manage this Joint Bid?

16 Can we deliver the final project without new Consortium members?

17 Can any required new members be recruited in time?

18 Do we have sufficient resources and team budget available to bid?

19 Can we prepare a professional bid in the time allowed?

2 Bidding Resource Availability Score: (Maximum of 25 points)

Percentage score:

Total number of scores rated as $\mathbf{0}$ (Very weak position for Consortium):

Total number of scores rated as Unk (Unknown):

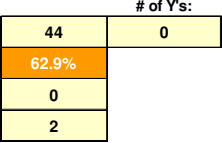

Action to Improve Scoring: We need to source an additional member with adult care home management skills in order to submit a bid as there is a requirem

Fig. 2 Example of Two Key Areas from a Completed Sell Side Go/No-Go Model

Demonstration Projects feedback indicated that it was a very useful model but it would be more user-friendly if it were automated either as an on online tool or as a downloadable template. Due to the confidentiality of information shared by consortium groups the downloadable template option was the preferred solution and work was completed in early 2016 to create this template using Microsoft Excel.

\section{Discussion and Conclusions}

The development of the PAM and Bid/ No Bid models started out as a field research project in 2012. This paper builds on the existing literature for managing consortium delivery in public procurement contracts. The results from the Demonstration Projects 
exceeded expectations and provided early feedback on the acceptability and usage of the new models included in the Joint Bidding Guide. Nine of the twelve procurements reached contract award stage during the study period and six of the contracts were awarded in part or fully to consortia. All but one of these consortia were newly-formed in order to bid for the procurements. If used appropriately alongside other advice in the Guide the two tools save resource and money for buyers and bidders, allowing better alignment of existing and new consortia to suitable opportunities.

Whilst this paper has explored the consortium concept and its application in the public procurement context, the findings are also relevant to the private sector. The study highlighted the importance of using a formal structured process for managing consortium delivery, taking account of the actions needed by both the buy and sell side. When managed effectively, using the tools available in the Joint Bidding Guide, business opportunities increase for SMEs and micro businesses working together as consortia networks (CNOs). This study provides empirical evidence that consortia can "build a collaborative advantage" [3]. The Welsh Government's Minister for Finance and Government Business endorsed this point by publicly highlighting the joint bidding programme's success in enabling small and micro businesses to win much larger public sector contracts than they could have accessed individually.

In 2016, the Welsh Government's procurement policy unit, Value Wales, and its collaborative procurement organization, the National Procurement Service won a highly commended award for innovation at one of the UK's national procurement awards. The Steering Group's lifespan has been extended to 2017 to capitalize on the program's overall success. All of the contracts awarded to consortia during the Demonstration Projects are still underway, and at the time of writing are being delivered successfully and creating significant community benefits. This bodes well for small businesses in the UK bidding for future public contracts and is an appropriate approach to the dispersed nature of a rural and mixed economy such as in Wales, where CNO members can be based far apart.

\section{References}

1. Stankovic, J.: Research directions for the internet of things. IEEE Internet of Things Journal Vol.1 (1), pp. 3-9. (2014)

2. Bettis, R., Hitt, M.: The new competitive landscape. Strategic management journal Vol. 16 (S1), pp. 7-19. (1995)

3. Baker, E., Kan, M. and Teo, S.: Developing a collaborative network organization: leadership challenges at multiple levels. Journal of Organizational Change Management, 24(6), pp.853-875. (2011)

4. Mason, R., Lalwani, C., Boughton, R.: Combining vertical and horizontal collaboration for transport optimisation. Supply Chain Management: An International Journal, Vol. 12 (3), pp.187-199. (2007)

5. Dai, Q., Kauffman, R.: B2B e-commerce revisited: Leading perspectives on the key issues and research directions. Electronic Markets, Vol. 12 (2), pp.67-83. (2002)

6. Walker, H., Preuss, L.: Fostering Sustainability through Sourcing from Smaller Businesses: Public Sector Perspectives. Journal of Cleaner Production. Vol. 16 (15), pp. 1600-1609. (2002)

7. Walker, H., Schotanus, F., Bakker, E., Harland, C.: Collaborative Procurement: A Relational View of Buyer-Buyer Relationships. Public Administration Review. 73 (4 July/August), pp. 588-598 (2013) 
8. Bakker, E., Walker, H., Schotanus, F., Harland, C.: Choosing an organisational form: the case of collaborative procurement initiatives. International journal of procurement management, Vol. 1 (3), pp.297-317. (2008)

9. Jost, G., Dawson, M., Shaw, D.: Private Sector Consortia Working for a Public Sector Client-Factors that Build Successful Relationships: Lessons from the UK. European Management Journal, Vol. 23(3), pp.336-350. (2005)

10. Cagnazzo, L., Taticchi, P., Bidini, G. Sameh, M.: Collaborative procurement within enterprise networks: a literature review, a reference framework and a case study. In Working Conference on Virtual Enterprises (pp. 351-360). Springer Berlin Heidelberg. (2009)

11. Rabelo R.J., Costa S.N., Romero D.: A Governance Reference Model for Virtual Enterprises. In: Camarinha-Matos, L.M., Afsarmanesh H. (eds) Collaborative Systems for Smart Networked Environments ICIP AICT, vol. 434, pp. 60-70. Springer, Heidelberg (2014)

12. Lynch, J., Uenk, N., Walker, H., Schotanus, F.: Community Benefits of Public Procurement: A Comparison between Wales (UK) and the Netherlands Local Governments. Conference Proceedings for $25^{\text {th }}$ IPSERA 2016. Dortmund, Germany. (2016)

13. Crossley, A., Coles, G., Edwards, R., Hurrell, S. Ruddle, N.: The Development and Adoption of a New Bidding System for Public Sector Contracts in Wales, In CamarinhaMatos, L.M., Benaben, F., Picard, W. (eds.) Risks and Resilience of Collaborative Networks. IFIP AICT, vol. 463 pp 622-630. Springer, Heidelberg (2015)

14. Joint Bidding Guide available at; http://gov.wales/docs/dpsp/publications/valuewales/151119-bidding-guide-en.pdf [Accessed 20 $0^{\text {th }}$ April 2016]

15. BS ISO/IEC 30105-3. Information technology. IT Enabled Services-Business Process Outsourcing (ITES-BPO) lifecycle processes. Part 3. Measurement framework and organizational maturity model.

16. BS 11000-1:2010 Framework specification for collaborative business relationships. BSi, Annex B \& C pp 35-38 (2010)

17. De Boer, L., Labro, E., Morlacchi, P.: A review of methods supporting supplier selection. European journal of purchasing \& supply management, 7(2), pp.75-89. (2001)

18. Karsak, E. Dursun, M.: Taxonomy and review of non-deterministic analytical methods for supplier selection. International Journal of Computer Integrated Manufacturing, 29(3), pp.263-286. (2016)

19. Bergman, M., Lundberg, S.: Tender evaluation and supplier selection methods in public procurement. Journal of Purchasing and Supply Management, 19(2), pp.73-83. (2013)

20. Falagario, M., Sciancalepore, F., Costantino, N., Pietroforte, R.: Using a DEA-cross efficiency approach in public procurement tenders. European Journal of Operational Research, 218(2), pp.523-529.(2012)

21. Blaikie, N.: Approaches to social enquiry: advancing knowledge. Cambridge. Polity Press (2000)

22. Mason, J.: Qualitative Researching. ${ }^{\text {nd }}$ Edition. London, Sage Publications. (2007)

23. Lessons Learned Report 2015. Available at; http://gov.wales/docs/dpsp/publications/valuewales/151119-lessons-learned-en.pdf [Accessed 20 $0^{\text {th }}$ April 2016]

24. BS 11000-2:2011 Collaborative Business Relationships - Part 2 BSi Table A1 (2011)

25. Sell2Wales available at; https://www.sell2wales.gov.wales/ [Accessed $20^{\text {th }}$ April 2016]

26. Public Procurement: Public Regulations available at; http://www.legislation.gov.uk/uksi/2015/102/pdfs/uksi_20150102_en.pdf [Accessed 21st April 2016] 